\title{
Article
}

\section{Squad management, injury and match performance in a professional soccer team over a Championship-winning season}

Carling, C., Le Gall, F., McCall, A., Nédélec, M., and Dupont, G. Available at http://clok.uclan.ac.uk/12298/

Carling, C. ORCID: 0000-0002-7456-3493, Le Gall, F., McCall, A., Nédélec, M., and Dupont, G. (2015) Squad management, injury and match performance in a professional soccer team over a Championship-winning season. European Journal of Sport Science, 15 (7). pp. 573-582. ISSN 1746-1391

It is advisable to refer to the publisher's version if you intend to cite from the work. http://dx.doi.org/10.1080/17461391.2014.955885

For more information about UCLan's research in this area go to http://www.uclan.ac.uk/researchgroups/ and search for <name of research Group>.

For information about Research generally at UCLan please go to http://www.uclan.ac.uk/research/

All outputs in CLoK are protected by Intellectual Property Rights law, including Copyright law. Copyright, IPR and Moral Rights for the works on this site are retained by the individual authors and/or other copyright owners. Terms and conditions for use of this material are defined in the policies page.

\section{CLoK}

Central Lancashire online Knowledge www.clok.uclan.ac.uk

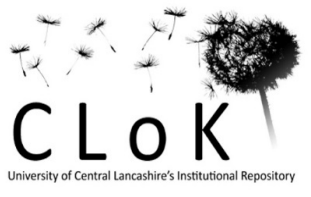


This is a pre-proof corrected manuscript, as accepted for publication, of an article published by Taylor \& Francis in European Journal of Sport Science on $12^{\text {th }}$ September 2014, available online:

http://www.tandfonline.com/doi/abs/10.1080/17461391.2014.955885?url_ver=Z39.88-

2003\&rfr_id=ori:rid:crossref.org\&rfr_dat=cr_pub\%3dpubmed\#.Vbd0ak3bLcs

\section{PLEASE REFER TO THE PUBLISHED VERSION FOR CITING PURPOSES}

Squad management, injury and match performance in a professional soccer team over a Championship-winning season

${ }^{1,2}$ Christopher Carling, ${ }^{2}$ Franck Le Gall, ${ }^{2,3}$ Alan McCall, ${ }^{2,3}$ Mathieu Nédélec, ${ }^{2,3}$ Gregory Dupont

Institutions:

${ }^{1}$ Institute of Coaching and Performance, University of Central Lancashire, UK

${ }^{2}$ LOSC Lille Métropole Football Club, LOSC Lab, Domain de Luchin, Camphin-en-Pévèle, 59780, France

${ }^{3}$ University of Lille Nord de France, UDSL, EA 4488, 9 rue de l'Université, Ronchin, 59790, France

Correspondence: Christopher Carling, LOSC Lille Métropole Football Club, Domain de Luchin, Camphin-en-Pévèle, 59780, France.

Phone: 00.33.6.0392 1863

Fax: 00.33.1.48910793

Email: chris.carling@free.fr

Running head: Performance in professional soccer 
Abstract

Squad management, injury and physical, tactical and technical match performance were investigated in a professional soccer team across five consecutive league seasons (2008-2013, 190 league games) with specific focus on a Championship-winning season (2010/11). For each player, match participation and time-loss injuries were recorded, the latter prospectively diagnosed by the team's physician. Defending and attacking tactical and technical performance indicators investigated included: ball possession and possession in opponents half, passes, forward passes, completed passes and forward passes, crosses and completed crosses, goal attempts and goal attempts on target, successful final third entries, free-kicks and 50/50 duels won/lost. Physical performance measures included: total distance and distance covered at high-speeds $(\geq 19.1 \mathrm{~km} / \mathrm{h})$. Results showed that during the 2010/11 season, squad utilisation was lowest potentially owing to the observed lower match injury occurrence and working days lost to injury thereby increasing player availability. In 2010/11, the team won both its highest number of points and conceded its lowest number of goals especially over the second-half of this season. The team also won its highest number of games directly via a goal from a substitute and scored and conceded a goal first on the highest and lowest number of occasions respectively. While multivariate analysis of variance detected a significant difference in some attacking and defensive performance indicators across the five seasons, these were generally not distinguishing factors in 2010/11. Similarly, univariate analyses of variance showed a significant difference in running distances covered across seasons but the trend was for less activity in 2010/11.

\section{Key words:}

Injury \& Prevention, Game Analysis, Performance, Team Sport, Technology 
Introduction

In professional soccer, the permanent quest for success necessitates the systematic collection, analysis and interpretation of information collected on player performance to guide decision-making and generate feedback for training prescriptions and match preparation strategies (Carling \& Court, 2012). As part of the contemporary coaching process, sports science and its associated scientific principles are used in an attempt to maximise player availability and individual performance for training and competition (Strudwick, 2012). However, metrics such as squad management in terms of player selection and rotation and the ability to remain injury free to ensure a high return especially in terms of availability for competition have received little or no attention in the sports science literature. Injury occurrence notably, results in decreased player availability and subsequent non-participation in match-play potentially impacts on team performance although contradictory observations exist (Árnason et al., 2004; Dauty \& Collon, 2011; Eirale, Tol, Farooq, Smiley, \& Chalabi, 2013; Hägglund et al. 2013). The association between squad management, player availability and injury and success in professional soccer therefore warrants further attention.

Similarly, researchers have also investigated the relationship between success represented by end of season league ranking in professional soccer and competitive physical performance determined via computerised time motion analyses. Two studies conducted in two professional European leagues respectively did not report an association between physical output and league ranking (Di Salvo, Gregson, Atkinson, Tordoff, \& Drust, 2009; Rampinini, Impellizzeri, Castagna, Coutts \& Wisløff, 2009). However, no information was provided by the authors on variations in physical efforts in relation to changes in league ranking across multiple seasons nor accounted for the potential effects of opposition running performance.

In competition contexts, there is a need for objective, factual and permanent records of factors underpinning team play (James, 2006). Match analysis is notably used to identify 'key performance indicators' (KPI) in an attempt to highlight and quantify technical and tactical aspects of play in 'successful' teams (Carling, Williams \& Reilly, 2009). Unfortunately, longitudinal data derived from game analyses over multiple seasons in successful teams are scarce (Di Salvo et al., 2009). Such data could provide more in-depth knowledge of how trends in KPI relate to success from season to season and especially in teams regularly placed at the top of their domestic League and/or those achieving success in European tournaments. In addition, the validity of data derived from some match analyses investigations, especially in the prescriptive function of analysing key tactical performance indicators, can be questioned due to a systematic lack of assessment of opposition interactions (Tenga, 2012). Thus, implications for defensive strategy and tactics are often only drawn via inference (Lago-Peñas, Lago-Ballesteros, \& Rey, 2011) and additional data are necessary particularly in relation to team success. Moreover, potential confounders such as the period of the season in which the data were collected, the quality of the opposition faced and match location should be accounted for in order to bring context to sample data and its subsequent conclusions which is often not the case (Mackenzie \& 
Cushion, 2013, Taylor, Mellalieu, James, \& Shearer, 2008). In the practical context, research is merited to evaluate whether during a particularly successful season for example, a team demonstrated improved performance in games against other top ranked teams, away from home, or over the latter half of the season.

Finally, in addition to KPI, analyses of competitive performance using simple match outcome descriptors relative to changes in match outcomes over the course of play are also lacking. Such descriptors can provide valuable information on a team's ability or inability to change the course of play and subsequently win games (Carling, Wright, Nelson \& Bradley, 2013). For example, potential questions include how many times over a season do top ranking teams score or concede first and how many points do they subsequently lose from a winning position or recover from a losing position respectively?

The aims of this study therefore were to investigate the aforementioned gaps in the research relating to squad management, injury, physical, tactical and technical performance and match outcome descriptors in a professional soccer team across five consecutive competitive domestic league seasons (2008-2013). Specific focus was placed on a championship-winning season (2010/11) in an attempt to identify performance-related components that potentially aided the team in winning its league.

Methods

Participants and match sample

Participation time in competition and injuries and physical, tactical and technical match performance were recorded in players belonging to a professional soccer team competing in the French Ligue 1. Altogether, 38 League games per season played over five consecutive seasons (2007/2008, 2009/2010, 2010/2011, 2011/12 and 2012/13: 190 games) were analysed. The club's coaching and medical staff remained unchanged over the five seasons while the physical conditioning coach changed once after the first season (2007/08).

While all data arose as a condition of employment in which player performance and injury were routinely measured over the course of the competitive season (Winter \& Maughan, 2009), approval for the study from the present club and ethics committee clearance from the University of Lille (France) were obtained.

Data collection procedures and competitive performance-related measures

A multiple camera semi-automatic computerised player tracking system (AMISCO Pro®, SportUniversal Process, Nice, France) was used to characterise match performance. KPI related to team technical and tactical performance defined in the AMISCO ${ }^{\circledR}$ Pro system and coded internally by trained company match-analysts included passes and forward passes, completed passes and completed forward passes, crosses and completed crosses, goal attempts and goal attempts on target, successful 
final third entries (defined as successful completion of a game action (e.g., pass, dribble) purposefully performed with the aim of continuing possession in the final third of the pitch [opponents defending third]), free-kicks and 50/50 duels won or lost.

Measures of physical performance included total distance covered (movement at speeds $\geq 0.7 \mathrm{~km} / \mathrm{h}$ ) and that ran at high-speeds (speeds $\geq 19.1 \mathrm{~km} / \mathrm{h}$ ) (Bradley et al., 2009). Physical performance data were available for 27 games in 2008/09, 26 in 2009/10, 27 in 2010/11, 23 in 2011/12 and 22 in 2012/13 as not all Ligue 1 opponent teams had access to the AMISCO Pro® system. The workings, accuracy and reliability of this system have been described elsewhere (Randers et al., 2010; Zubillaga, 2006, Rodriguez de la Cruz, Croisier, \& Bury, 2010).

Injuries sustained were prospectively diagnosed and documented by the club's physician. Inclusion criteria were those injuries leading to a player being unable to fully participate in future training and/or matches (i.e. time-loss injury). Players were considered injured until the physician allowed full participation in collective training and availability for match selection. Match injuries included those sustained when members of the club's professional squad participated in either firstteam or reserve team competition. Injury incidence was calculated as the number of injuries per 1000 hours exposure to training and matches. Injuries were classed according to mechanism: non-contact and contact event. Finally, the cumulated number of games and working days (training/matches) and the proportion of the squad unavailable due to injury were recorded. The methodologies and definitions of injury used closely follow those recommended by Fuller et al. (2006).

\section{Statistical Analyses}

All statistical analyses were conducted using SPSS for Windows Version 13.0 (SPSS Inc., Chicago, IL, USA). Data are presented as means and standard deviations unless otherwise stated. Data for both attacking and defending KPI respectively were analysed using multivariate analyses of variance (MANOVA) with playing season the between subject factor. Two-way MANOVAs tested for interactions between playing season and season half (before and after Christmas break), opposition team ranking (using final league position) and game location (home/away) respectively. Altogether, 26 dependent measures of attacking (including points won) and 15 defending measures were included in the analysis (see Table 2). To compare physical performance, two-way ANOVAs were employed to test for differences in the total distance run and that covered at high-intensities between the reference team compared to opponents across each season. Finally, differences across seasons for injury-related variables were tested using a one-way MANOVA. Follow-up univariate analyses using Bonferronicorrected pair wise comparisons were used where appropriate. The level of significance was set at $\mathrm{p}<0.05$. Effect sizes for statistically significant post hoc test differences were determined. The magnitude of the ES was interpreted as trivial $(<0.2)$, small $(>0.2-0.6)$, moderate $(>0.6-1.2)$, large (>1.2-2.0) and very large (>2.0-4.0) (Batterham \& Hopkins, 2006). 
Results

Analysis of league rankings, points won, goals scored and conceded and match outcomes

Over the five seasons, the highest number of points obtained by the reference team was observed in the Championship winning season (2010/11: 76) although there was no significant difference in points won across seasons $(\mathrm{p}=0.643$ ) (Table 1). In 2010/11, the team obtained 14 points in 10 games against top ranked opposition teams (based on final league position of the 5 other best-ranked teams) and 62 points in 28 games against all lower-ranked teams respectively $(2012 / 13=10,52 ; 2011 / 12=12$, 62; 2009/10=13, 57 and 2008/09=12, 52 respectively). Despite MANOVA showing no difference in the number of goals scored $(\mathrm{p}=0.233)$ or conceded $(\mathrm{p}=0.994)$ across seasons, the lowest number of goals conceded (36) and best goal difference in away games (+9) respectively were nevertheless observed during the 2010/11 season while the best overall goal difference was recorded in the 2011/12 season (+33). The 2010/11 season also saw the lowest number of losses overall (4) and in both home (1) and away (3) games respectively. In all seasons except 2008/09, there was an increase in the number of points won per game for the second half of the season with the largest augmentation $(+0.4$ points won per game) observed in 2010/11. Regarding goals conceded, 2010/11 was the only season in which a drop (-0.4 goals conceded per game) across the second half of the season occurred.

Descriptive analysis of match outcomes (Table 1) showed that over the course of the 2010/11 season, the reference team scored at least one goal, did not concede a goal and scored first on a greater number of occasions (34, 11 and 27). This particular season also saw the team concede a goal first on the lowest number of occasions (9), lose the least (1 [joint with the 2012/13 season]) and win the largest amount of its games in the final 15-minutes of play (7 [joint best score with 2011/12]) and win its highest number of games (5) directly via a goal from a substitute player.

Analysis of squad utilisation

The lowest utilisation of the total squad in first-team competition was observed in 2010/11: $84.0 \%$ compared to $89.2 \%$ in $2008 / 09,84.6 \%$ in $2009 / 10,85.2 \%$ in $2011 / 12$ and $89.3 \%$ in $2012 / 13$ respectively ( 21 versus 25, 22, 23 and 25 players used). Over the course of the 2010/11 season, 10 players participated in at least $75 \%$ of the total minutes of league competition played by the club compared to 6 players in 2008/09 and 2009/10, 5 in 2011/12 and 4 in the 2012/13 seasons respectively.

Analysis of technical and tactical attacking and defending performance

The analysis of attacking KPI revealed a significant main effect for playing season $\mathrm{F}(96$, 644.279) $=2.335$, Wilks' lambda $=.306, p<0.001$. Significant differences $(p<0.05-p<0.001)$ across seasons were observed for KPI including: \% time in possession overall and in the first-half and final 15 -minutes of play respectively and the number of crosses, passes and forward passes, \% passes 
completed and \% forward passes completed and free-kicks won (Table 3). Notable post hoc differences included greater ball possession, passing frequency and completion rates in seasons 3,4 and 5 (effect size range for differences: 0.65-1.46). Occurrences of free-kicks won and crosses peaked in 2008/09 (effect size range for differences: 0.65-0.92). For attacking KPI, there was no interaction between season and game location $\mathrm{F}(96,505.627)=1.205$, Wilks' lambda $=.442, \mathrm{p}>0.05$, season half $\mathrm{F}(96,505.627)=1.006$, Wilks' lambda $=.500, \mathrm{p}>0.05$ or opposition team ranking $\mathrm{F}(96,505.627)=1.253$, Wilks' lambda $=.808, \mathrm{p}>0.05$.

The analysis of defending KPI revealed a significant main effect for playing season F(92, 647.670 $)=2.052$, Wilks' lambda $=.363, \mathrm{p}<0.001$. Significant differences $(\mathrm{p}<0.05-\mathrm{p}<0.001)$ were reported for pass and forward pass completion rates and the frequency of free-kicks conceded by the reference team (Table 4). Highest values were observed in the 2012/13 season for pass completion and forward pass completion (effect size range for differences: 0.63-0.73) whereas the frequency of freekicks conceded was highest in 2008/09 (effect size range for differences: 0.72-1.33). For defending KPI, there was no interaction between season and game location $F(92,509.136)=0.887$, Wilks' lambda $=.555, \mathrm{p}>0.05$, season half $\mathrm{F}(92,509.136)=1.004$, Wilks' lambda $=.517, \mathrm{p}>0.05$ or opposition team ranking $\mathrm{F}(92,509.136)=1.093$, Wilks' lambda $=.490, \mathrm{p}>0.05$.

Analysis of physical performance

Two-way ANOVA revealed a difference $(\mathrm{p}<0.001)$ in total distance covered and in high-speed running ( $\mathrm{p}=0.007$ ) over the five seasons for the reference team and its direct opponents (Table 3). Post hoc tests demonstrated that the reference team covered a greater overall distance (both $\mathrm{p}<0.01$ ) and at high-speeds ( $<<0.01$ and $p<0.05$ ) compared to its opposition in 2008/09 and 2009/10 (effect sizes for differences ranged from 0.62 to 1.08 ) while no difference was observed for the other seasons. No interaction $(\mathrm{p}=0.253)$ was observed between team and playing season for the total distance covered whereas high-speed running varied across seasons $(\mathrm{p}=0.007)$. A greater distance was covered by opposition teams in seasons 4 and 5 compared to season 1 (both $\mathrm{p}<0.001$, effect sizes for differences: $1.24 \& 1.57$ ) while this was not the case for the reference team.

\section{Analysis of injury}

Multivariate analysis of injury related variables revealed a significant main effect for season $\mathrm{F}(40$, 138.263) $=2.740$, Wilks' lambda $=.109, \mathrm{p}<0.001$. Statistical differences across seasons were observed for the overall incidence of injury, incidence of injury in training and competition, incidence of noncontact injuries and joint sprains and muscle strains, percentage of working days lost to injury and the percentage of the squad that was unavailable due to injury $(\mathrm{p}<0.01-\mathrm{p}<0.001)$. A trend for peak values in all these variables was observed for the 2008/09 season (Table 4).

Discussion 
In this study, squad management, injuries and physical, tactical and technical performance were compared in a professional soccer team across five consecutive competitive seasons. This comparison was done in an attempt to identify potential distinguishing performance-related components over the course of a Championship winning season.

Squad management, notably selection and rotation, and player availability (particularly remaining injury free) are key issues in coping with the high demands of contemporary training and match-play (Strudwick, 2013). In the present team, the lowest utilisation of the playing squad (84.0\%) and largest number of players who participated in at least $75 \%$ of the total minutes of league competition (10) were observed in the 2010/11 Championship winning season. These metrics imply that the team's coaching staff was able to call upon and select the same players, hence similar starting line-ups, for league competition more frequently compared to the other seasons. A reasonable explanation for the higher player availability was the club's injury situation over the course of the 2010/11 season. In comparison to the other seasons, match and contact injury rates, number of matches missed and the proportion of the squad unavailable for either training or matches due to injury were lower. Also of interest was the peak in both the percentage of the squad unavailable and number of working days lost due to injury during the two least successful seasons (2007/08 and 2012/13: $5^{\text {th }}$ and $6^{\text {th }}$ league rankings respectively).

In light of these results, it would not be unreasonable to suggest that higher player availability and the ability to remain injury free made a substantial contribution to the reference team winning the 2010/11 Championship. Similar research in Icelandic (Arnason et al., 2004) and Qatari (Eirale et al., 2013) elite soccer has also identified an association between league rankings and injury rates. Hägglund et al. (2013) reported that lower injury incidence and player availability had a significant influence on points won per match in domestic league competition in 24 top flight male European professional soccer clubs. Interestingly, the highest injury incidences (match and training) in the reference club were observed in the first season (2008/09). At the commencement of the following season, systematic controlled functional injury prevention and rehabilitation protocols and post-match recovery strategies were implemented (Carling, Le Gall, \& Dupont, 2012). These strategies no doubt aided in achieving lower injury rates and aiding player recovery between games thereby aiding greater player availability across subsequent seasons.

Analysis of results across seasons showed that the reference team won its highest number of points overall and most points in games against other high ranked teams, conceded its lowest number of goals and achieved its lowest number of losses during the 2010/11 season. In addition, the reference team scored at least one goal per game and did not concede a goal on the largest number of occasions. While an augmentation in the number of points won per game for the second half of the season was reported across all seasons (except 2008/09), the largest increase was observed in 2010/11. This improvement in points won can be linked to the number of goals conceded per game as 2010/11 was the only season in which a drop (-0.4 goals) across the second half of the season occurred. While no 
significant changes in any of the defensive (or attacking) tactical and technical KPI occurred over the second half of this particular season, it seems that an improvement in defensive play, represented by a drop in goals conceded over the second part of the season, largely contributed to the reference team in winning its league in 2010/11.

Other notable results observed in 2010/11 compared to the other seasons included the reference team scoring first and not conceding a goal first on the highest and lowest number of occasions respectively and losing the least amount of games in the final 15-minutes of play. Further noteworthy observations occurring in 2010/11 include a peak in the number of games won by the team in the final 15-minutes of play (jointly with 2011/12) and the highest and lowest amount of goals scored and conceded (the latter jointly with 2012/13) respectively in second-half injury time (11.7\% vs. $2008 / 09=9.8 \%$ vs. $2009 / 10=5.6 \%$ vs. $2011 / 12=5.6 \%$ vs. $2012 / 13=5.1 \%$ ). These results suggest that the team's ability to score first and maintain defensive and attacking performance until the end of match-play was paramount. Similarly, the number of games won directly via a goal from a substitute peaked in 2010/11 highlighting the importance of the contributions of outfield players entering play late on (Carling \& Bloomfield, 2010, Bradley, Lago-Peñas, \& Rey, 2014). Taken together, these results demonstrate the utility of simple match outcome descriptors in providing information on a team's ability (or inability) to change the course of game results (Carling et al., 2013).

Analysis of frequencies and completion rates in attacking KPI such as passes, crosses, penalty area entries, set-plays, goal attempts as well as time spent in ball possession has received widespread coverage especially in relation to match outcomes and attaining success (Carling \& Court, 2012). Rankings data for all French Ligue 1 teams over the entire 2010/11 season (Soumbou, personal communication, data not shown) showed that the reference team was ranked in the top 3 clubs for the frequency of goals scored, goal attempts, goal attempts on target and goal attempts per goal scored as well as for the percentage of time spent in ball possession and percentage of completed passes and crosses. These results generally agree with findings in studies that report a link between 'successful' performance and KPI such as the frequency of goal attempts and goal attempts on target (Castellano, Casamichana, \& Lago, 2012; Lago-Peñas, Lago-Ballesteros, Dellal, \& Gómez, 2010), time spent in ball possession (Jones, James, \& Mellalieu, 2004; Lago-Peñas et al., 2011) and pass completion rates (Collet, 2013; Oberstone, 2009). In contrast and perhaps surprisingly however, the team's performance in virtually all of the selected attacking KPI was not highest during the Championship winning year despite a statistically significant difference across the five seasons. Only the ratio of goal attempts on target to goals scored (derived using data in Table 1) was best in 2010/11 (3.0 versus 4.2 in 2008/09, 3.3 in 2009/10, 3.3 in 2011/12 \& 3.3 in 2012/13). This result partly confirms that attacking success at elite levels can be linked to a greater efficiency in converting goal attempts into goals (Collet, 2013; Rampinini et al, 2009).

In consideration of these results, it would seem that frequency and success rates in the key attacking variables used here were generally unable to explain the success of the present team in 
2010/11 in comparison to the other four seasons. Two reasonable explanations can be put forward for these findings. First, KPI can only promote a rudimentary understanding of sports performance and provide limited information about the self-organisation and constraints underlying techniques and behaviours that produce performance outcomes (Glazer, 2010). Match analysis research frequently employs a 'reductionist approach' to establish causal relationships between isolated attacking performance variables in an attempt to predict game outcomes as variables are measured as a result of availability rather than to develop a deeper understanding of performance (Mackenzie \& Cushion, 2013). Second, this method does not acknowledge potentially confounding variables or provide sufficient context to the variable itself (Lago, 2009). However, three common confounding factors, game location (home versus away) and opposition team ranking (e.g., high versus low ranked clubs) and period in the season (before and after Christmas break) did not statistically influence any of the selected measures of technical and tactical attacking (nor defending) performance in the reference team across seasons. Additional research investigating the reference team's style and patterns of play (e.g., counter-attacking style, elaborate build-up play, second-phase plays) in relation to effectiveness in creating goal-scoring opportunities, scoring goals and winning games across the five seasons would be pertinent (Tenga, Holme, Ronglan \& Bahr, 2010; Tenga, Ronglan, \& Bahr, 2010). Inferences can nevertheless be made indirectly regarding playing style as both the lowest number of goals scored from a set-play situation (10,15\% of total) and the highest number of goals scored in the 6-yard penalty area (21,31\% of total) respectively were observed in the 2010/11 Championship winning season (data not shown). This result infers that the reference team's ability to score goals directly from open-play situations and create and take chances close to goal were important distinguishing features of attacking play in 2010/11.An improvement in defending performance (represented by the number of goals conceded particularly over the $2^{\text {nd }}$ part of the season) could tentatively be interpreted as playing a more important part in achieving success in 2010/11 in comparison to attacking play. While, match analysis research frequently neglects evaluation of defensive KPI related to success in elite soccer, some studies have reported substantially lower frequencies of goal attempts and goal attempts on target (Castellano Casamichana, \& Lago, 2012) and crosses (Lago-Peñas, et al., 2010) conceded by more successful teams. In the present study however, KPI frequencies such as goal attempts and goal attempts on target, final third entries and successful crosses conceded by the reference team were not at their lowest in 2010/11 suggesting that these were not useful discriminators of successful defensive play. In contrast, when data presented in Table 2 are again expressed in terms of the ratio of goal attempts to goals conceded, goal attempts on target to goals conceded, penalty area entries to goals conceded and percentage of completed crosses conceded, all these substantially improved in 2010/11. Thus, the team's ability in preventing goal scoring opportunities from penalty area entries and crosses as well as not conceding despite an opposition attempt on target was fundamental. These findings reflect the need to evaluate the efficiency of game related events rather than simple frequencies (Hughes \& Bartlett, 2002) and again concord that efficiency in game actions is a better predictor of 
match outcomes (Collet, 2013). Future research might consider whether defensive success in terms of fewer goals and goal attempts conceded in successful teams is related to other factors such as better defensive balance (Tenga, 2012).

Finally, time motion analyses of match running demonstrated a significant difference accompanied by moderate effect sizes in the distance covered in high-speed running over the five seasons between the reference team and its opponents. High-speed distance covered by the reference team was statistically greater in seasons 1 and 2 but not in seasons 3, 4 and 5 in comparison to opponent teams. In contrast, performance in this particular component did not vary individually for the reference team across the 5 seasons. Although these data generally suggest that players in a Top team in French professional football should be able to cover similar or greater distances at high-speeds compared to their direct opponents, running performance actually dropped during the two most successful seasons in terms of League ranking. Unfortunately, time motion analysis data were unavailable for every match played thus caution is necessary when interpreting these findings. Nevertheless, rankings for the 2010/11 season show that the team was only ranked 8th out of 19 French Ligue 1 clubs for high-speed running although again data were unavailable for every match (Carling, 2013). Taken together, these results tend to support previous conclusions that high-speed running per se is unrelated to success in professional soccer (Di Salvo, Pigozzi, González-Haro, Laughlin, \& De Witt, 2013; Bradley et al., 2013, Carling, 2013).

Conclusions

To our knowledge this is the only study to date to compare squad management, injury, and physical, tactical and technical performance in a professional soccer team across five consecutive competitive seasons with the aim of providing new insights into potential distinguishing performancerelated components over the course of a Championship-winning season thus generating knowledge for training and preparation. While no single component can be highlighted, higher player availability for selection linked to the ability to remain injury free combined with improved defensive (represented by a reduction in goals conceded) rather than attacking performance almost certainly made an important contribution. Before any generalisations can be made in an attempt to establish a winning performance model, similar longitudinal data are required from a larger pool of domestic Championship-winning teams. 


\section{References}

Árnason, Á., Sigurdsson, S.B., Gudmundsson, A., Holme I., Engebretsen L., \& Bahr, R. (2004). Physical fitness, injuries, and team performance in soccer. Medicine \& Science in Sports \& Exercise. 36, 278-285. doi: 10.1136/bjsports-2012-091040

Batterham, A.M., \& Hopkins, W.G. (2006). Making meaningful inferences about magnitudes. International Journal of Sports Physiology \& Performance. 1, 50-57. PMID:19114737

Bradley, P.S., Carling, C., Gomez Diaz, A., Hoode, P., Barnes, C., Ade, J., ... Mohr, M. (2013). Match Performance and Physical Capacity of Players in the Top Three Competitive Standards of English Professional Soccer. Human Movement Science, 32, 808-821. doi: 10.1016/j.humov.2013.06.002.

Bradley P.S., Lago-Peñas, C., \& Rey E. (2014). Evaluation of the Match Performances of Substitution Players in Elite Soccer. International Journal of Sports Physiology \& Performance, 9, 415-424. doi: 10.1123/ijspp.2013-0304.

Bradley, P.S., Sheldon, W., Wooster, B., Olsen, P., Boanas P., \& Krustrup, P. (2009). High-intensity running in FA Premier League soccer matches. Journal of Sports Sciences. 27, 159-168. doi: $10.1080 / 02640410802512775$.

Carling, C. (2013). Interpreting physical performance in professional soccer match-play: should we be more pragmatic in our approach? Sports Medicine. 43, 655-663. doi: 10.1007/s40279-013-0055-8.

Carling, C. \& Bloomfield, J. (2010). Work-rate of substitutes in elite soccer: a preliminary study. Journal of Science and Medicine in Sport. 13, 253-255. doi: 10.1016/j.jsams.2009.02.012.

Carling, C. \& Court, M. (2012). Match \& Motion Analysis of Soccer. In M. Williams (Ed.), Science and Soccer: Developing Elite Performers (pp 173-198). London: Routledge.

Carling, C., Le Gall, F., \& Dupont, G. (2011). Are physical performance and injury risk in a professional soccer team in match-play affected over a prolonged period of fixture congestion? International Journal of Sports Medicine. 33, 36-42. doi: 10.1055/s-0031-1283190

Carling, C., Reilly, T. \& Williams, A.M. (2009). Performance Assessment for Field Sports. London: Taylor and Francis.

Carling, C., Wright, C., Nelson, L., \& Bradley, P.S. (2013). Comment on 'Performance analysis in football: A critical review and implications for future research'. Journal of Sports Science, 32, 2-7. doi: 10.1080/02640414.2013.807352.

Castellano, J., Casamichana, D. \& Lago, C. (2012). The Use of Match Statistics that Discriminate Between Successful and Unsuccessful Soccer Teams. Journal of Human Kinetics, 31, 139-147. doi: 10.2478/v10078-012-0015-7.

Collet, C. (2013). The possession game? A comparative analysis of ball retention and team success in European and international football, 2007-2010. Journal of Sports Science. 31, 123-36. doi: 10.1080/02640414.2012.727455.

Dauty, M. \& Collon S. (2011). Incidence of injuries in French professional soccer players. International Journal of Sports Medicine, 32, 965-969. doi: 10.1055/s-0031-1283188.

Di Salvo, V., Gregson, W., Atkinson, G., Tordoff, P., \& Drust, B. (2009). Analysis of high intensity activity in Premier League soccer. International Journal of Sports Medicine, 30, 205-212. doi: 10.1055/s-0028-1105950.

Di Salvo, V., Pigozzi, F., González-Haro, C., Laughlin, M.S., \& De Witt, J.K. (2013). Match Performance Comparison in Top English Soccer Leagues. International Journal of Sports Medicine. 34, 526-532. doi: 10.1055/s-0032-1327660.

Eirale, C., Tol, J.L., Farooq A., Smiley, F., \& Chalabi, H. (2013). Low injury rate strongly correlates with team success in Qatari professional football. British Journal of Sports Medicine. 47, 807-808. doi: 10.1136/bjsports-2012-091040.

Fuller, C.W., Ekstrand, J., Junge, A., Andersen, T.E., Bahr, R., Dvorak, J., ... Meeuwisse, W.H. (2006). Consensus statement on injury definitions and data collection procedures in studies of football (soccer) injuries. British Journal of Sports Medicine, 40, 193-201. doi: 10.1136/bjsm.2005.025270.

Glazier, P.S. (2010) 'Game, set and match? Substantive issues and future directions in performance analysis. Sports Medicine, 40, 625-634. doi: 10.2165/11534970-000000000-00000 
Hägglund, M., Waldén, M., Magnusson, H., Kristenson, K., Bengtsson, H., \& Ekstrand, J. (2013). Injuries affect team performance negatively in professional football: an 11-year follow-up of the UEFA Champions League injury study. British Journal of Sports Medicine, 47, 738-742. doi: 10.1136/bjsports-2013-092215.

Hughes, M.D. \& Bartlett, R.M. (2002). The use of performance indicators in performance analysis. Journal of Sports Sciences, 20, 739-754. doi:10.1080/026404102320675602.

James, N. (2006). The role of notational analysis in soccer coaching. International Journal of Sports Science and Coaching, 1, 185-198. 10.1260/174795406777641294.

Jones, P., James, N., \& Mellalieu, S. (2004). Possession as a performance indicator in soccer. International Journal of Performance Analysis in Sport, 4, 98-102. DOI: $10.1080 / 026404102320675602$.

Lago, C. (2009). The influence of match location, quality of opposition, and match status on possession strategies in professional association football. Journal of Sports Sciences, 27, 1463-1469. doi: 10.1080/02640410903131681.

Lago-Peñas C., Lago-Ballesteros, J., Dellal, A. \& Gómez, M. (2010). Game-related statistics that discriminated winning, drawing and losing teams from the Spanish soccer league. Journal of Sports Science and Medicine 9, 288-293. PMCID: PMC3761743.

Lago-Peñas, C., Lago-Ballesteros, J. \& Rey, E. (2011). Differences in performance indicators between winning and losing teams in the UEFA Champions League. Journal of Human Kinetics, 27, 135-146. DOI: 10.2478/v10078-011-0011-3.

Mackenzie, R., \& Cushion, C. Performance analysis in football: A critical review and implications for future research. Journal of Sports Sciences, 31, 639-676. doi: 10.1080/02640414.2012.746720.

Oberstone, J. (2009). Differentiating the top English Premier League football clubs from the rest of the pack: identifying the keys to success. Journal of Quantitative Analysis in Sports, 5, Article 10. DOI: 10.2202/1559-0410.1183.

Rampinini, E., Impellizzeri, F.M., Castagna, C., Coutts, A.J., \& Wisløff, U. (2009). Technical performance during soccer matches of the Italian Serie A league: Effect of fatigue and competitive level. Journal of Science \& Medicine in Sport. 12, 227-233. doi:10.1016/j.jsams.2007.10.002.

Randers, M.B., Mujika, I., Hewitt, A., Santisteban, J., Bischoff, R., Solano R., ... Mohr, M. (2010). Application of four different football match analysis systems: A comparative study. Journal of Sports Sciences, 28, 171-182. doi: 10.1080/02640410903428525.

Rodriguez de la Cruz, C., Croisier, J., \& Bury, T. Validation du système d'analyse de match AMISCO(TM): une étude préliminaire. Actes du 5ème Colloque international "Football et recherche technologie et performance, 95-96: 5ème Colloque international "Football et recherche - technologie et performance" 19-20-21 mai 2010, Grenoble, France.

Strudwick, T. Contemporary issues in the physical preparation of elite players. (2013) In: M. Williams (Ed.), Science \& Soccer III. London: Routledge, pp 335-356.

Taylor, J.B., Mellalieu, S.D., James, N. \& Shearer, D.A. (2008). The influence of match location, quality of opposition, and match status on technical performance in professional association football. Journal of Sports Sciences 26, 885-895. doi: 10.1080/02640410701836887.

Tenga, A. Soccer. (2012) In: O’Donoghue, P., Sampaio, J. \& McGarry, T. (Eds.), Handbook of Performance Analysis of Sport. London: Routledge, pp. 323-337.

Tenga A, Holme I, Ronglan LT, Bahr R. (2010). Effect of playing tactics on achieving score-box possessions in a random series of team possessions from Norwegian professional soccer matches. Journal of Sports Sciences. 28, 245-255. doi: 10.1080/02640410903502766.

Tenga, A., Ronglan, L.T. \& Bahr, R. (2010). Measuring the effectiveness of offensive match play in professional soccer. European Journal of Sport Science 10, 269-277. DOI: $10.1080 / 17461390903515170$

Winter, E.M., \& Maughan, R.J. (2009). Requirements for ethics approvals. Journal of Sports Sciences, 27, 985. DOI: $10.1080 / 02640410903178344$.

Zubillaga, A. (2006). La actividad del jugador de fútbol en alta competición: análisis de variabilidad. (Unpublished doctoral dissertation). Malaga University of Sport Sciences and Exercise, Malaga, Spain. 
Table 1 League rankings, points won, goals scored and conceded and match outcome descriptors across five competitive seasons

\begin{tabular}{|c|c|c|c|c|c|}
\hline \multirow[b]{2}{*}{ Reference team } & \multicolumn{5}{|c|}{ Competitive season } \\
\hline & $2008 / 09$ & $2009 / 10$ & $2010 / 11$ & $2011 / 12$ & $2012 / 13$ \\
\hline Final League ranking & 5 & 4 & 1 & 3 & 6 \\
\hline Home & 2 & $1^{\#}$ & 1 & 4 & 6 \\
\hline Away & $8^{\#}$ & 6 & 1 & 2 & 6 \\
\hline Points won (top ranked team) & $64(80)$ & $70(78)$ & $76(76)$ & $74(82)$ & $62(83)$ \\
\hline Home & $41(47)$ & $45(45)$ & $44(44)$ & $41(50)$ & $34(43)$ \\
\hline Away & $23(42)$ & $25(33)$ & $32(32)$ & $33(34)$ & $28(40)$ \\
\hline $\mathrm{N}^{\circ}$ Wins & 17 & 21 & 21 & 21 & 16 \\
\hline Home & 12 & 14 & 13 & 12 & 9 \\
\hline Away & 5 & 7 & 8 & 9 & 19 \\
\hline $\mathrm{N}^{\circ}$ Draws & 13 & 7 & 13 & 11 & 14 \\
\hline Home & 5 & 3 & 5 & 5 & 7 \\
\hline Away & 8 & 4 & 8 & 6 & 7 \\
\hline $\mathrm{N}^{\circ}$ Losses & 8 & 10 & 4 & 6 & 8 \\
\hline Home & 2 & 2 & 1 & 2 & 3 \\
\hline Away & 6 & 8 & 3 & 4 & 7 \\
\hline $\mathrm{N}^{\circ}$ goals scored & 51 & 72 & 68 & 72 & 59 \\
\hline Home & 34 & 44 & 40 & 48 & 32 \\
\hline Away & 17 & 28 & 28 & 24 & 27 \\
\hline $\mathrm{N}^{\circ}$ goals conceded & 39 & 40 & 36 & 39 & 40 \\
\hline Home & 20 & 15 & 17 & 23 & 16 \\
\hline Away & 19 & 25 & 19 & 16 & 24 \\
\hline Overall goal difference & +12 & +32 & +32 & +33 & +19 \\
\hline Home & +14 & +29 & +23 & +25 & +16 \\
\hline Away & -2 & +3 & +9 & +8 & +3 \\
\hline Games in which scored & 30 & 33 & 34 & 33 & 30 \\
\hline Games in which did not concede & 15 & 13 & 11 & 14 & 10 \\
\hline Games in which no score draw & 5 & 1 & 2 & 3 & 3 \\
\hline Games in which conceded first & 11 & 14 & 9 & 13 & 15 \\
\hline Games won after conceding first & 2 & 3 & 4 & 5 & 4 \\
\hline Games drawn after conceding first & 4 & 4 & 2 & 2 & 4 \\
\hline Games lost after conceding first & 5 & 7 & 3 & 6 & 7 \\
\hline Points recovered after conceding first & 10 & 13 & 14 & 17 & 16 \\
\hline Games in which scored first & 22 & 23 & 27 & 22 & 20 \\
\hline Games lost after scoring first & 3 & 3 & 1 & 0 & 1 \\
\hline Drawn games after scoring first & 4 & 2 & 9 & 6 & 7 \\
\hline Games won after scoring first & 15 & 18 & 17 & 16 & 12 \\
\hline Points lost from winning position & 13 & 11 & 12 & 6 & 10 \\
\hline Games won in last 15 mins & 6 & 4 & 7 & 7 & 4 \\
\hline Games lost in last 15 mins & 2 & 2 & 1 & 2 & 1 \\
\hline Games won directly by substitutes & 1 & 2 & 5 & 1 & 3 \\
\hline Goals scored by substitutes & 7 & 9 & 8 & 8 & 6 \\
\hline
\end{tabular}


\# = equal League ranking with another team

Table 2 Analysis of tactical and technical attacking and defending performance indicators across 5 competitive seasons

\begin{tabular}{|c|c|c|c|c|c|c|c|}
\hline \multirow[b]{2}{*}{ Attacking/Defending indicators } & \multicolumn{5}{|c|}{ Competitive season } & \multirow{2}{*}{$\begin{array}{l}\text { Statistical } \\
\text { difference }\end{array}$} & \multirow{2}{*}{$\begin{array}{c}\text { Post hoc } \\
\text { (Bonferoni test) }\end{array}$} \\
\hline & 2008/09 (S1) & $2009 / 10(\mathrm{~S} 2)$ & 2010/11 (S3) & 2011/12 (S4) & 2012/13 (S5) & & \\
\hline Goals scored & $1.3 \pm 1.0$ & $1.9 \pm 1.4$ & $1.8 \pm 1.4$ & $1.9 \pm 1.3$ & $1.6 \pm 1.2$ & $\mathrm{p}=0.233$ & \\
\hline Goals conceded & $1.0 \pm 1.0$ & $1.1 \pm 1.0$ & $0.9 \pm 0.8$ & $1.0 \pm 1.2$ & $1.1 \pm 0.9$ & $\mathrm{p}=0.994$ & \\
\hline Goal attempts & $15.2 \pm 4.5$ & $15.7 \pm 5.2$ & $14.8 \pm 5.4$ & $14.4 \pm 5.1$ & $14.0 \pm 4.0$ & $\mathrm{p}=0.601$ & \\
\hline 1 st half & $6.9 \pm 2.6$ & $7.2 \pm 2.8$ & $7.3 \pm 3.6$ & $7.1 \pm 3.3$ & $6.7 \pm 2.7$ & $\mathrm{p}=0.902$ & \\
\hline 2st half & $8.3 \pm 3.1$ & $8.5 \pm 3.9$ & $7.6 \pm 4.0$ & $7.4 \pm 3.5$ & $7.3 \pm 3.0$ & $\mathrm{p}=0.470$ & \\
\hline Goal attempts conceded & $10.4 \pm 4.1$ & $10.6 \pm 4.6$ & $10.6 \pm 4.5$ & $9.8 \pm 4.2$ & $9.2 \pm 3.5$ & $\mathrm{p}=0.543$ & \\
\hline 1st half & $4.8 \pm 2.3$ & $5.2 \pm 2.7$ & $4.8 \pm 2.5$ & $4.8 \pm 2.8$ & $4.0 \pm 2.2$ & $\mathrm{p}=0.350$ & \\
\hline 2st half & $5.6 \pm 2.7$ & $5.4 \pm 2.7$ & $5.8 \pm 3.0$ & $5.0 \pm 2.9$ & $5.2 \pm 2.3$ & $\mathrm{p}=0.759$ & \\
\hline Goal attempts on target & $5.5 \pm 2.4$ & $6.2 \pm 3.0$ & $5.4 \pm 3.4$ & $6.2 \pm 2.9$ & $5.2 \pm 1.8$ & $\mathrm{p}=0.397$ & \\
\hline Goal attempts on target conceded & $3.7 \pm 2.1$ & $3.8 \pm 2.6$ & $3.9 \pm 2.4$ & $3.6 \pm 1.9$ & $3.4 \pm 2.0$ & $\mathrm{p}=0.917$ & \\
\hline$\%$ Goal attempts on target & $37.1 \pm 13.2$ & $39.0 \pm 12.2$ & $34.9 \pm 13.7$ & $43.5 \pm 15.5$ & $38.9 \pm 14.9$ & $\mathrm{p}=0.098$ & \\
\hline$\%$ Goal attempts on target conceded & $36.2 \pm 18.5$ & $36.5 \pm 16.4$ & $36.0 \pm 19.4$ & $37.2 \pm 15.8$ & $37.1 \pm 15.9$ & $\mathrm{p}=0.998$ & \\
\hline Final third entries & $53.1 \pm 11.3$ & $53.6 \pm 15.0$ & $54.7 \pm 11.3$ & $57.4 \pm 14.2$ & $58.9 \pm 15.9$ & $\mathrm{p}=0.274$ & \\
\hline Final third entries conceded & $41.1 \pm 11.4$ & $42.4 \pm 12.0$ & $42.3 \pm 15.7$ & $39.0 \pm 9.6$ & $42.6 \pm 16.5$ & $\mathrm{p}=0.752$ & \\
\hline Crosses & $27.2 \pm 7.9$ & $26.7 \pm 9.9$ & $21.9 \pm 7.8$ & $22.2 \pm 7.3$ & $23.9 \pm 7.1$ & $\mathrm{p}=0.008$ & $\mathrm{~S} 1^{\mathrm{c}}>\mathrm{S} 3$ \\
\hline Crosses conceded (\%) & $19.0 \pm 6.4$ & $17.0 \pm 5.7$ & $16.9 \pm 6.1$ & $15.4 \pm 5.9$ & $15.8 \pm 6.3$ & $\mathrm{p}=0.338$ & \\
\hline Crosses completed (\%) & $23.8 \pm 8.2$ & $20.7 \pm 8.0$ & $23.6 \pm 10.4$ & $22.8 \pm 8.8$ & $21.2 \pm 8.9$ & $\mathrm{p}=0.441$ & \\
\hline Crosses completed conceded (\%) & $21.0 \pm 12.0$ & $22.6 \pm 13.2$ & $19.6 \pm 8.8$ & $25.9 \pm 11.8$ & $22.1 \pm 8.3$ & $\mathrm{p}=0.151$ & \\
\hline Ball possession & $52.0 \pm 4.9$ & $53.8 \pm 5.0$ & $56.3 \pm 5.9$ & $57.2 \pm 5.9$ & $55.3 \pm 6.6$ & $\mathrm{p}=0.001$ & $\mathrm{~S} 3^{\mathrm{c}} \& \mathrm{~S} 4^{\mathrm{a}}>\mathrm{S} 1$ \\
\hline 1st half & $52.1 \pm 5.8$ & $54.6 \pm 4.9$ & $57.6 \pm 7.0$ & $58.3 \pm 6.9$ & $56.3 \pm 7.0$ & $\mathrm{p}<0.001$ & $\mathrm{~S} 3^{\mathrm{b}}, \mathrm{S} 4^{\mathrm{a}} \& \mathrm{~S} 5^{\mathrm{c}}>\mathrm{S} 1$ \\
\hline 2 st half & $51.9 \pm 6.3$ & $53.3 \pm 6.6$ & $55.0 \pm 7.4$ & $56.0 \pm 7.5$ & $54.1 \pm 7.3$ & $\mathrm{p}=0.119$ & \\
\hline Final 15 mins & $50.4 \pm 8.3$ & $52.0 \pm 10.0$ & $52.3 \pm 8.4$ & $56.9 \pm 9.7$ & $54.3 \pm 10.4$ & $\mathrm{p}=0.033$ & $\mathrm{~S} 4^{\mathrm{c}} \mathrm{vS} 1$ \\
\hline Opposition half & $42.3 \pm 5.3$ & $42.1 \pm 6.5$ & $41.6 \pm 6.3$ & $43.3 \pm 7.4$ & $39.2 \pm 7.0$ & $\mathrm{p}=0.089$ & \\
\hline Own half conceded & $39.3 \pm 5.3$ & $39.2 \pm 5.4$ & $39.8 \pm 6.2$ & $39.2 \pm 4.6$ & $36.5 \pm 5.7$ & $\mathrm{p}=0.079$ & \\
\hline Passes & $442.5 \pm 76.9$ & $475.6 \pm 91.4$ & $520.6 \pm 81.7$ & $564.4 \pm 97.7$ & $566.1 \pm 90.7$ & $\mathrm{p}<0.001$ & $\mathrm{~S} 3^{\mathrm{b}}, \mathrm{S} 4^{\mathrm{a}} \& \mathrm{~S} 5^{\mathrm{a}}>\mathrm{S} 1 ; \mathrm{S} 4^{\mathrm{a}} \& \mathrm{~S} 5^{\mathrm{a}}>\mathrm{S} 2$ \\
\hline Passes completed (\%) & $71.6 \pm 5.7$ & $72.2 \pm 5.4$ & $77.3 \pm 5.1$ & $78.5 \pm 5.1$ & $77.9 \pm 4.7$ & $\mathrm{p}<0.001$ & $\mathrm{~S} 3^{\mathrm{a}}, \mathrm{S} 4^{\mathrm{a}}, \mathrm{S} 5^{\mathrm{a}}>\mathrm{S} 1 ; \mathrm{S}^{\mathrm{a}}, \mathrm{S} 4^{\mathrm{a}}, \mathrm{S}^{\mathrm{a}}>\mathrm{S} 2$ \\
\hline Forward Passes & $300.1 \pm 45.6$ & $314.6 \pm 44.7$ & $337.2 \pm 51.1$ & $362.8 \pm 56.5$ & $361.6 \pm 54.6$ & $\mathrm{p}<0.001$ & $\mathrm{~S}^{\mathrm{c}}, \mathrm{S}_{4}^{\mathrm{a}}, \mathrm{S} 5^{\mathrm{a}}>\mathrm{S} 1 ; \mathrm{S}^{\mathrm{a}} \& \mathrm{~S}^{\mathrm{a}}>\mathrm{S} 2$ \\
\hline Forward passes completed (\%) & $65.0 \pm 6.8$ & $65.9 \pm 6.4$ & $71.0 \pm 6.3$ & $72.4 \pm 6.3$ & $72.3 \pm 5.4$ & $\mathrm{p}<0.001$ & $\mathrm{~S} 3^{\mathrm{c}}, \mathrm{S} 4^{\mathrm{a}}, \mathrm{S}^{\mathrm{a}}>\mathrm{S} 1 ; \mathrm{S} 3^{\mathrm{b}}, \mathrm{S} 4^{\mathrm{a}} \& \mathrm{~S} 5^{\mathrm{a}}>\mathrm{S} 2$ \\
\hline Passes conceded & $393.5 \pm 58.3$ & $388.3 \pm 53.2$ & $398.6 \pm 82.7$ & $394.4 \pm 71.4$ & $462.6 \pm 86.5$ & $\mathrm{p}=0.150$ & \\
\hline Completed conceded & $67.6 \pm 5.7$ & $67.3 \pm 6.9$ & $70.3 \pm 7.0$ & $70.0 \pm 6.0$ & $71.5 \pm 6.2$ & $\mathrm{p}=0.016$ & $\mathrm{~S} 5^{\mathrm{c}}>\mathrm{S} 2$ \\
\hline Forward passes conceded & $270.5 \pm 37.5$ & $269.3 \pm 3.1$ & $275.0 \pm 51.1$ & $263.7 \pm 41.9$ & $281.2 \pm 50.3$ & $\mathrm{p}=0.075$ & \\
\hline Forward passes completed conceded (\%) & $59.6 \pm 6.7$ & $60.1 \pm 6.8$ & $63.3 \pm 8.1$ & $62.1 \pm 6.5$ & $64.6 \pm 6.8$ & $\mathrm{p}=0.010$ & $\mathrm{~S} 5^{\mathrm{c}}>\mathrm{S} 1$ \\
\hline $\mathrm{N}^{\circ}$ Free-kicks won & $19.7 \pm 5.0$ & $18.3 \pm 4.8$ & $17.3 \pm 4.3$ & $18.8 \pm 4.2$ & $15.3 \pm 4.4$ & $\mathrm{p}=0.001$ & $\mathrm{~S} 1^{\mathrm{a}}, \mathrm{S} 2^{\mathrm{c}} \& \mathrm{~S} 4^{\mathrm{c}}>\mathrm{S} 5$ \\
\hline $\mathrm{N}^{\circ}$ Free-kicks conceded & $19.3 \pm 4.7$ & $17.1 \pm 4.2$ & $13.8 \pm 3.5$ & $14.7 \pm 3.9$ & $14.2 \pm 3.8$ & $\mathrm{p}<0.001$ & $\mathrm{~S} 1^{\mathrm{a}} \& \mathrm{~S} 2^{\mathrm{c}}>\mathrm{S} 5 ; \mathrm{S} 1^{\mathrm{a}} \& \mathrm{~S} 2^{\mathrm{b}}>\mathrm{S} 3 ; \mathrm{S} 1^{\mathrm{a}}>\mathrm{S} 4$ \\
\hline Duels won $(\%)$ & $51.8 \pm 6.5$ & $53.0 \pm 6.1$ & $50.5 \pm 7.1$ & $52.6 \pm 6.2$ & $54.1 \pm 7.4$ & $\mathrm{p}=0.205$ & \\
\hline 1st half & $52.2 \pm 11.0$ & $51.7 \pm 8.7$ & $50.1 \pm 10.3$ & $53.8 \pm 8.7$ & $53.7 \pm 11.6$ & $\mathrm{p}=0.477$ & \\
\hline 2st half & $51.5 \pm 7.2$ & $54.1 \pm 8.0$ & $50.9 \pm 8.8$ & $51.6 \pm 8.9$ & $54.5 \pm 11.6$ & $\mathrm{p}=0.281$ & \\
\hline Final 15 mins & $50.2 \pm 12.5$ & $56.3 \pm 16.9$ & $55.0 \pm 14.0$ & $56.5 \pm 15.1$ & $58.1 \pm 17.1$ & $\mathrm{p}=0.205$ & \\
\hline
\end{tabular}


Table 3 Analysis of physical performance across five competitive seasons

\begin{tabular}{|c|c|c|c|c|c|}
\hline \multirow[b]{2}{*}{ Physical performance } & \multicolumn{5}{|c|}{ Competitive season } \\
\hline & $2008 / 09$ & $2009 / 10$ & $2010 / 11$ & $2011 / 12$ & $2012 / 13$ \\
\hline \multicolumn{6}{|c|}{ Total distance run $(\mathrm{m} / \mathrm{min})$} \\
\hline Reference team & $121.4 \pm 3.5^{*}$ & $120.5 \pm 3.8^{*}$ & $118.0 \pm 4.5$ & $120.7 \pm 4.7$ & $120.8 \pm 5.1$ \\
\hline Opponents & $117.4 \pm 3.8$ & $116.5 \pm 5.0$ & $116.5 \pm 4.9$ & $119.7 \pm 4.8$ & $119.1 \pm 4.4$ \\
\hline \multicolumn{6}{|c|}{ High-intensity running $(\mathrm{m} / \mathrm{min})$} \\
\hline Reference team & $9.8 \pm 1.0^{*}$ & $10.4 \pm 1.1^{\#}$ & $10.0 \pm 1.8$ & $10.5 \pm 1.8$ & $10.7 \pm 1.6$ \\
\hline Opponents & $8.7 \pm 1.1$ & $9.5 \pm 1.7$ & $9.6 \pm 1.4$ & $10.4 \pm 1.6^{\sim}$ & $10.6 \pm 1.3^{\sim}$ \\
\hline
\end{tabular}

$\mathrm{m} / \mathrm{min}=$ distance covered per minute

$*$ = statistical difference between reference team and opponent performance $(\mathrm{p}<0.01)$

\# = statistical difference between reference team and opponent performance $(\mathrm{p}<0.05)$

$\sim=$ statistical difference across seasons for opponent performance $(p<0.001)$ 
Table 4 Analysis of injury across five competitive seasons

\begin{tabular}{|c|c|c|c|c|c|c|c|}
\hline \multirow[b]{2}{*}{ Injury data } & \multirow[b]{2}{*}{ 2008/09 (S1) } & \multicolumn{3}{|c|}{ Competitive season } & \multirow[b]{2}{*}{ 2012/13 (S5) } & \multirow{2}{*}{$\begin{array}{l}\text { Statistical } \\
\text { difference }\end{array}$} & \multirow[b]{2}{*}{ Post hoc (Bonferoni test) } \\
\hline & & $2009 / 10(\mathrm{~S} 2)$ & 2010/11 (S3) & $2011 / 12(\mathrm{~S} 4)$ & & & \\
\hline Overall incidence of injury* & $14.4 \pm 3.0$ & $8.7 \pm 2.8$ & $7.8 \pm 2.3$ & $7.0 \pm 3.2$ & $7.4 \pm 2.6$ & $\mathrm{p}<0.001$ & $\mathrm{~S} 1>\mathrm{S} 2^{\mathrm{a}}=\mathrm{S}^{\mathrm{a}}=\mathrm{S} 4^{\mathrm{a}}=\mathrm{S}^{\mathrm{a}}$ \\
\hline Incidence of training injury & $7.3 \pm 3.0$ & $2.8 \pm 2.3$ & $3.2 \pm 1.7$ & $2.0 \pm 1.3$ & $3.0 \pm 2.4$ & $\mathrm{p}<0.001$ & $\mathrm{~S} 1>\mathrm{S} 2^{\mathrm{a}}=\mathrm{S} 3^{\mathrm{b}}=\mathrm{S} 4^{\mathrm{a}}=\mathrm{S} 5^{\mathrm{b}}$ \\
\hline Incidence of match injury & $77.3 \pm 27.2$ & $49.6 \pm 21.7$ & $33.0 \pm 11.1$ & $45.1 \pm 25.3$ & $34.3 \pm 11.9$ & $\mathrm{p}<0.001$ & $\mathrm{~S} 1>\mathrm{S} 2^{\mathrm{c}}=\mathrm{S} 3^{\mathrm{a}}=\mathrm{S} 4^{\mathrm{b}}=\mathrm{S} 5^{\mathrm{a}}$ \\
\hline Incidence of contact injury & $4.1 \pm 1.4$ & $4.4 \pm 2.4$ & $2.6 \pm 2.2$ & $3.0 \pm 1.7$ & $2.1 \pm 1.5$ & $\mathrm{p}=0.176$ & \\
\hline Incidence of non contact injury & $9.3 \pm 3.5$ & $4.3 \pm 1.8$ & $5.1 \pm 2.0$ & $4.0 \pm 2.0$ & $5.3 \pm 2.2$ & $\mathrm{p}<0.001$ & $\mathrm{~S} 1>\mathrm{S} 2^{\mathrm{a}}=\mathrm{S} 3^{\mathrm{b}}=\mathrm{S} 4^{\mathrm{a}}=\mathrm{S} 5^{\mathrm{b}}$ \\
\hline Incidence of muscle strains & $5.2 \pm 2.9$ & $2.5 \pm 1.4$ & $3.7 \pm 1.9$ & $3.1 \pm 2.7$ & $2.4 \pm 1.1$ & $\mathrm{p}=0.011$ & $\mathrm{~S} 1>\mathrm{S} 2^{\mathrm{c}} \mathrm{S} 5^{\mathrm{c}}$ \\
\hline Incidence of ankle sprains & $3.3 \pm 1.8$ & $1.9 \pm 1.7$ & $0.8 \pm 1.4$ & $0.8 \pm 0.8$ & $1.4 \pm 1.4$ & $\mathrm{p}=0.002$ & $\mathrm{~S} 1>\mathrm{S} 3^{\mathrm{b}}=\mathrm{S} 4^{\mathrm{b}}$ \\
\hline Average layoff time per injury (days) & $10.7 \pm 22.7$ & $9.9 \pm 18.8$ & $7.9 \pm 9.1$ & $11.3 \pm 19.0$ & $10.6 \pm 15.2$ & $\mathrm{p}=0.838$ & \\
\hline Average $n^{\circ}$ games missed due to injury & $11.7 \pm 4.0$ & $12.9 \pm 9.1$ & $6.2 \pm 3.8$ & $10.4 \pm 5.6$ & $13.5 \pm 4.5$ & $\mathrm{p}=0.051$ & \\
\hline Average $\mathrm{n}^{\circ}$ working days missed due to injury & $14.8 \pm 2.7$ & $8.6 \pm 3.2$ & $6.8 \pm 2.6$ & $8.1 \pm 2.6$ & $9.5 \pm 3.8$ & $\mathrm{p}<0.001$ & $\mathrm{~S} 1>\mathrm{S} 2^{\mathrm{a}}=\mathrm{S} 3^{\mathrm{a}}=\mathrm{S} 4^{\mathrm{a}}=\mathrm{S} 5^{\mathrm{c}}$ \\
\hline$\%$ squad unavailable due to injury & $26.0 \pm 7.3$ & $14.1 \pm 5.1$ & $14.0 \pm 5.7$ & $16.0 \pm 6.7$ & $21.1 \pm 7.7$ & $\mathrm{p}<0.001$ & $\mathrm{~S} 1>\mathrm{S} 2^{\mathrm{b}}=\mathrm{S} 3^{\mathrm{b}}=\mathrm{S} 4^{\mathrm{c}}=\mathrm{S} 5$ \\
\hline
\end{tabular}

*Injury incidence $=$ number of injuries per 1000 hours of exposure to play

${ }^{\mathrm{a}}=\mathrm{p}<0.001$
${ }^{\mathrm{b}}=\mathrm{p}<0.01$
${ }^{\mathrm{c}}=\mathrm{p}<0.05$ 